\title{
Stochastic Reliability Measurement and Design Optimization of an Inventory Management System
}

\author{
Abdulaziz T. Almaktoom \\ Department of Operations and Information Management, Effat University, P.O. Box 34689, Jeddah 21478, Saudi Arabia \\ Correspondence should be addressed to Abdulaziz T. Almaktoom; atalmaktoom@gmail.com
}

Received 1 March 2017; Revised 7 June 2017; Accepted 27 June 2017; Published 30 August 2017

Academic Editor: Dominik T. Matt

Copyright ( 2017 Abdulaziz T. Almaktoom. This is an open access article distributed under the Creative Commons Attribution License, which permits unrestricted use, distribution, and reproduction in any medium, provided the original work is properly cited.

\begin{abstract}
Inventory management systems and dynamic reliability measures and controls remain challenging at every stage, especially when time variances and operating conditions are considered. An inventory management system must maintain its adeptness over time while coping with the uncertainty of inventory flow. Unexpected delays during inventory movement can harm the reliability and robustness of the entire system. This paper introduces a method of quantifying the reliability of an inventory management system. Also, a novel, reliability-based robust design optimization model has been developed to optimally allocate and schedule time while considering uncertainty associated with inventory movement. The processes involved include purchasing, shipping, receiving, tracking, warehousing, storage, and turnover. A case study of a furniture company in Saudi Arabia is presented to demonstrate the efficacy of the model.
\end{abstract}

\section{Introduction}

The globalization of today's marketplace has brought new opportunities and challenges to industry. This new frontier allows businesses to reach more consumers than ever. However, it also increases the need for reliable, robust global inventory management systems. Technology has become an effective management recordkeeping tool. Many variables associated with managing stock can ultimately determine the success or failure of a business. Thus, an effective inventory management system is essential. Sani [1] revealed that inventory management is used to specify inventory inflows and outflows. It defines the quantity of stock arriving and being registered into the system. It must be able to recognize valuable information. The challenge is to develop a method that aids in evaluating inventory management while coping with unforeseen conditions. Inventory consists of stock, which may include raw materials, work-in-progress, finished, or value-added products or services [1]. Having a good inventory management system aids in maintaining a good record of stock keeping units (SKUs). Hence, maintaining a precise stock level where the system-recorded stock reflects the actual stock is essential to avoid errors [2].
Technology has advanced rapidly, improving several fields of endeavor such as education and business. During the mid-1990s, various companies started to evaluate inventory management system software. This software could document processes and changes as products were transported in and out of any business. In the early 2000s, inventory management solution technology expanded from the small scale to the large. Before this type of industrial innovation, many businesses had to record the products sold and received each day on paper and assemble the resulting documents into a folder for recordkeeping. Orders were placed using handwritten notes, resulting in inefficient business processes.

Inventory management systems are suitable for all types of businesses that deal with tracking and identification of inventory. The main objective of such a system is to determine and maintain the inventory level by preserving records of the products sold and by keeping sales records by date. Companies use inventory management systems to prevent out-ofstock and overstock issues.

An inventory manager might face two major problems: having an overstock of inventory or having a shortage. Excess inventory automatically becomes overstock. This causes problems for businesses and has many negative 
consequences. One important effect is an increase in cost. Storage and security fees increase and money is invested in nonessential goods. There is also risk involved in holding excess inventory. There are two costs associated with holding inventory. Carrying (or holding) cost is the cost of storage, insurance, material handling, and so forth. The second type of cost is ordering cost. This is the cost associated with placing orders and receiving goods such as transportation and shipping and receiving and inspecting materials. These two costs represent the core of inventory problems. An order size increase can lead to an increase in the average number of processed goods in inventory and thus increased carrying costs.

On the other hand, stock shortages can also have dire consequences. Business reputations rely on consumer trust. Providing high-quality, affordable goods in a timely and predictable manner is key to success. As a result, a stock shortage can lead to massive losses. These losses can stem from increased production times and purchasing costs, loss of sales, and ultimately the loss of customer goodwill. Inventory decision-making is very risky, as it may impact the supply chain [3]. An inventory management system is necessary to satisfy customer demand at the right time and in a costeffective manner $[4,5]$. Hence, maintaining too little stock may result in production problems while having too much means investing significant money unnecessarily. Inventory is one of the most expensive assets that many companies invest in. It is a critical investment and therefore the heart of any enterprise.

This research introduces a method that can be used to evaluate the reliability of an inventory system with regard to satisfying consumer demand. The resulting measure can be used in organizing and scheduling via reliability-based robust design optimization. The remainder of this section reviews current literature on inventory management system evaluation and design methods.

This paper develops a novel reliability measure and reliability-based robust design optimization (RBRDO) approach. Reliability focuses on the subset stimulation technique to achieve numerical efficiency [6]. Reliability is described as the tendency towards consistency of performance and responsibility or as the fulfillment of a service provider's promises to customers. Reliability deals with the performance and dependability of the service entity in meeting customer requests. A service is considered to be reliable if it repeatedly shows similar results using comparable measures [7]. Moreover, services have to be provided at the time promised in order to maintain credibility [8]. RBRDO provides both cost-effective manufacturing processes and target confidence $[9,10]$. Probabilistic constraints are the key constraints in RBRDO. They create several numerical challenges with regard to numerical efficiency, stability, accuracy, and so forth [11-13]. RBRDO is very important for structural optimization because many of its practical applications involve at least two conflicting objectives, typically including low cost and high reliability [14]. The constraints are influenced by both functional and reliability requirements.

Reliability-based robust design optimization (RBRDO) combines of reliability-based design optimization (RBDO) and robust design optimization (RDO). In general, reliability is defined as the ability to start and continue to operate [15]. Robustness was first introduced by Taguchi in 1987 to help find solutions that are less sensitive to unknown variations. Taguchi's definition of a robust design is "a product whose performance is minimally sensitive to factors causing variability." Byrne and Taguchi [16] illustrated the main objective of RDO, which is to find a design with minimum scattering model variance in order to produce results near the mean values of the design parameters. Roos et al. mentioned that RDO can be treated as statistical variability in parameter design [17]. Different methods [18-21] were developed in order to systematically treat uncertainties in engineering analysis and more recently for RBRDO method development. RBRDO can be used a design tool when the function and performance of a product are relatively insensitive to variation [22].

There is limited research available on method development for inventory management system evaluation and design optimization. In [23], Axsäter showed how approximate evaluation can be applied to inventory system policies. Another research [24] investigated hybrid techniques for evaluating life-cycle inventories. In [25], Resurreccion and Santos developed multiobjective prioritization methodologies for inventory system evaluation. The study helped to determine inventory enhancement priorities with user preference and resource availability as new dimensions. Arıkan et al. [26] investigated the interrelation between transportation uncertainties and inventory system performance. In [27] researchers provided a new method which eliminates the unbalanced benefit distributions caused by vendor managed inventory and offers almost equal benefits to the participating firms. A modified particle swarm optimization to solve integrated location and inventory control problems in a twoechelon supply chain network was introduced in [28]. In [29] researchers proposed a long-term extreme price risk measure method for inventory portfolios. Despite numerous inventory management system evaluation studies, further research on inventory systems associated with design optimization and reliability evaluation has rarely been reported. Therefore, this paper presents a model for inventory management system evaluation. A RBRDO approach is developed to help in satisfying reliability requirements in every stage of the system, while coping with uncertainty and minimizing overall handling and management cost. The remainder of this paper is organized as follows: Section 2 introduces methods of evaluating inventory system reliability and presents the methodology developed to design reliable, robust inventory systems. Section 3 evaluates the model described in this paper by applying it to a case study of a furniture company in Jeddah, Saudi Arabia. Conclusions are presented in Section 4.

\section{Materials and Methods}

This section explains the research design, which includes the evaluation method, optimization model, and data collection procedures. Three key research questions were addressed to achieve the previously mentioned research objectives:

(1) How can all inventory system processes be evaluated using a single, unique measure? 


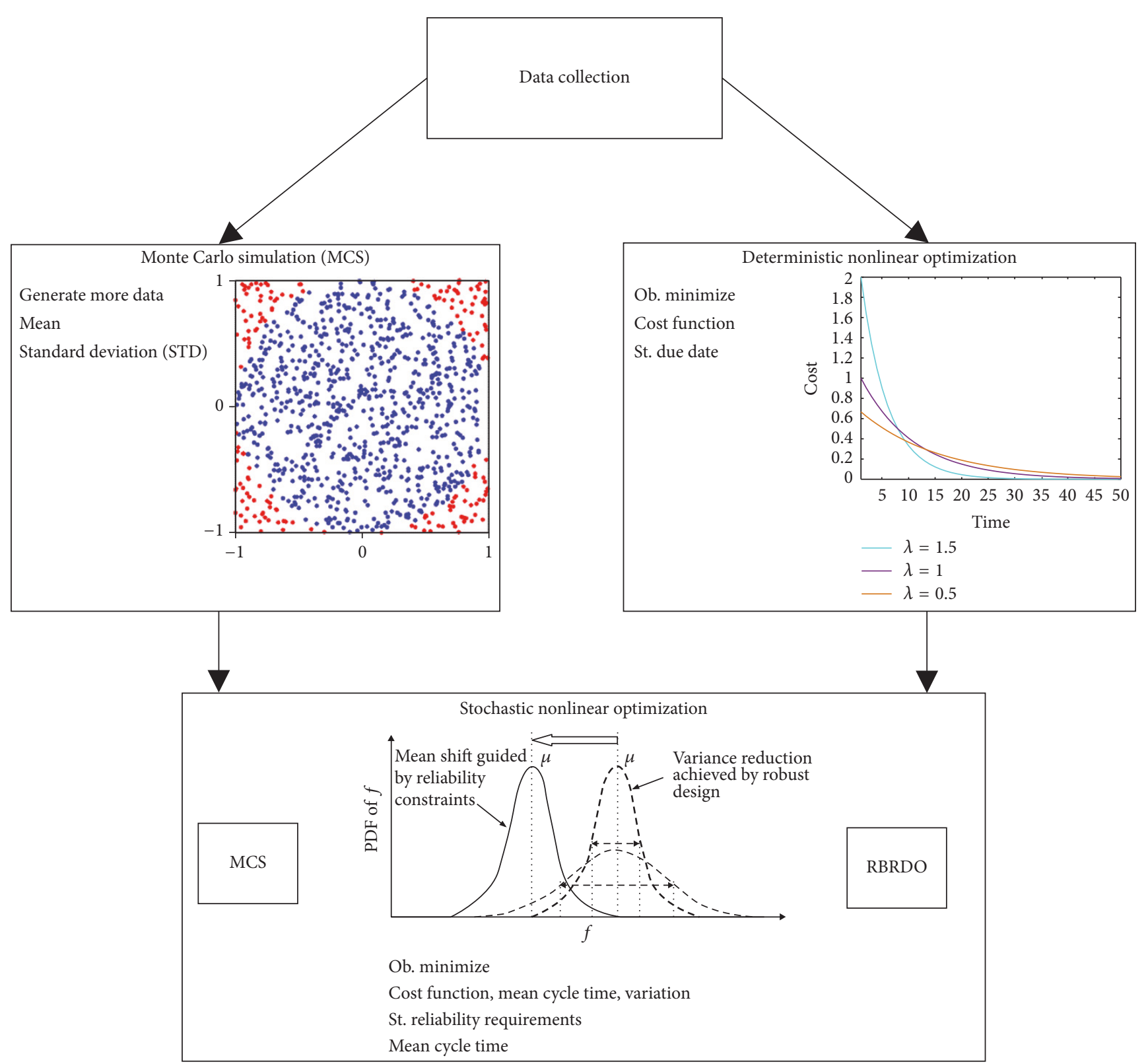

FIGURE 1: RBRDO procedure applied to an inventory management system.

(2) How to evaluate the reliability of an inventory management system?

(3) How to design a cost-efficient, reliable, robust inventory management system while coping with uncertainty?

Numerous techniques were considered in answering these questions. They include Monte Carlo simulation, linear programming, deterministic nonlinear programing, stochastic nonlinear programing, and RBRDO. Microsoft Excel solver and MATLAB were used for modeling and mathematical simulation. The goal was to investigate the most basic approach that can be used to achieve the objectives of this research. Thus, this investigation started by using basic tools such as linear programing and Excel solver and moved on to advanced technologies such as stochastic nonlinear programing and MATLAB. This helped us to understand a variety of available design and optimization tool capabilities. The methods and tools used to achieve the research objective are shown in Figure 1.

2.1. Inventory Management System Reliability (IMSR) Evaluation Model. Progression and development of an IMSR measure is affected by both internal factors and numerous external factors such as increasing globalization, information availability, global trade, and ecological concerns. The reliability of an inventory system can be defined as its ability to complete all required processes before they are due. Figure 2 shows the IMSR phenomenon. 


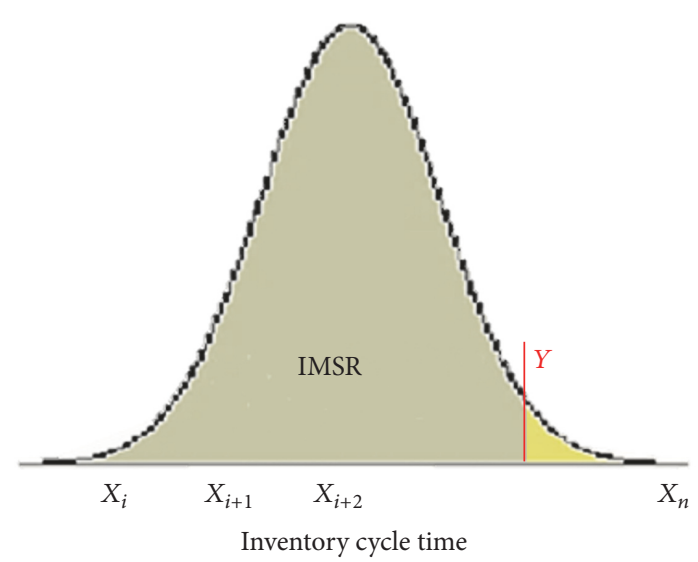

Figure 2: Typical IMSR phenomenon.

The IMSR should be measured and compared using a qualified set of performance measures. In order to control system performance, the process parameters must be kept within a limited range. This makes comparisons of target and actual performances possible. Once comparisons have been made, specific processes can be targeted to improve inventory management performance.

By using an appropriate set of measures, the overall IMSR can be closely monitored for performance. Successive improvements can be applied to each task in the system in order to determine their impacts on the overall IMSR. The IMSRs of suppliers, routes, factories, and the overall inventory management system can be used to achieve customer satisfaction. In general, the IMSR can be defined as the probability of completing all required process at time $(X)$ before the due time $(Y)$ and can be expressed statistically as shown in

$$
\text { IMSR }=\operatorname{Pr}\left(X_{1}+X_{2}+\cdots+X_{n} \leq Y\right)
$$

Mathematically, the IMSRs of suppliers, factory, routes, distribution centers, ports, and the overall inventory management system are represented by the ratio of the total cycle time minus the cumulative delay to the total cycle time. The total cycle time is the cumulative time taken from order placement until receipt and assembly at the customer location. Cumulative delay is the delay due to uncertainty during movement of products through the inventory system. The IMSR can be obtained using

$$
\begin{aligned}
\operatorname{IMSR}_{X(i, j)}= & \left(Y-\left(f_{X(i, j)} \sum_{j=1}^{J} \sum_{i=1}^{I} \sigma_{X(i, j)}+f_{X(i, j)} \sum_{j=1}^{J} \sum_{i=1}^{I} \tau_{X(i, j)}\right)\right) \\
& \times \frac{1}{Y}
\end{aligned}
$$

$$
\text { when } Y \leq\left(f_{X(i, j)} \sum_{j=1}^{J} \sum_{i=1}^{I} \sigma_{X(i, j)}+f_{X(i, j)} \sum_{j=1}^{J} \sum_{i=1}^{I} \tau_{X(i, j)}\right), Y_{X(i, j)}=0 \text {, }
$$

where $\operatorname{IMSR}_{X(i, j)}$ represents the reliability performance of node type $X$ (e.g., port, supplier, and route), number $i$ in level $j$. $Y$ represents the time due and $\sigma_{X(i, j)}$ is the standard deviation (uncertainty) of the distribution function of node

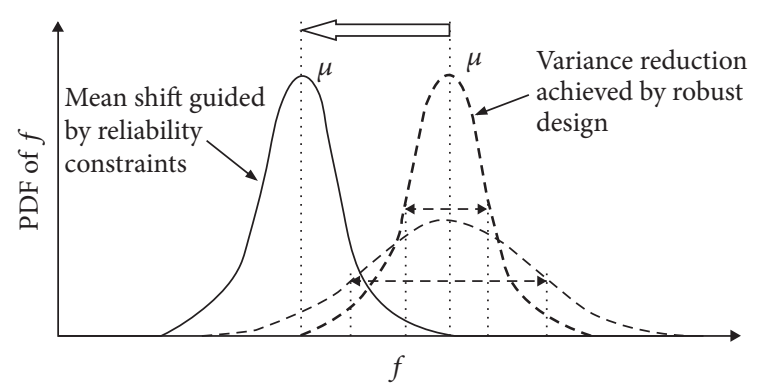

Figure 3: Typical RBRDO phenomenon.

type $X$ number $i$ in level $j . \tau_{X(i, j)}$ is the external factor delay affecting the node. When the sum of the delay $\left(\tau_{X(i, j)}\right)$ and uncertainty $\left(\sigma_{X(i, j)}\right)$ are larger than the due time $(Y)$, the reliability $\left(\operatorname{IMSR}_{X(i, j)}\right)$ equals zero.

2.2. RBRDO of an Inventory Management System. This subsection presents the RBRDO of an Inventory Management System. In general, this approach characterizes uncertainty variables and failure modes to optimize a design for higher reliability [30]. RBRDO accepts variability and uses the limit state function to separate the stress and strength probability density functions (PDFs) to achieve the desired reliability level. The objective of performing RBRDO on an inventory system is to minimize variation while satisfying inventory system requirements. It also helps to find the best compromise between cost and reliability by taking uncertainties into account. Furthermore, RBRDO is used to shift reliability and reduce variance by designing a multiobjective function that minimizes cost and cost uncertainty factors (variance) with the required reliability target as a constraint, as shown in Figure 3 [31].

The optimal design of an inventory system can be determined using RBRDO, which seeks to find designs that are less sensitive to the uncontrollable variations that are often inherent to the design process. RBRDO outperforms existing deterministic discrete optimization tools when change or uncertainty is involved in optimization problems. Application of RBRDO to the design of an inventory management system has three objectives: minimization of cost, inventory cycle time, and the impact of uncertainty.

RBRDO considers various uncertainties introduced by changes in specifications, transportation delays, raw material availability, manufacturing processes, and operational conditions. Ensuring performance reliability and robustness in terms of time and cost is of vital importance for inventory management systems.

The general formula for the RBRDO of an inventory management system is given by the following:

$$
\begin{array}{r}
\text { Minimize: } \mathbf{W}_{c} * f_{X(i, j)} \sum_{j=1}^{J} \sum_{i=1}^{I} C_{X(i, j)}+\mathbf{W}_{\mu} \\
* f_{X(i, j)} \sum_{j=1}^{J} \sum_{i=1}^{I} \mu_{X(i, j)}+\mathbf{W}_{\sigma}
\end{array}
$$


TABLE 1: Company design parameters.

\begin{tabular}{|c|c|c|c|c|c|}
\hline Number & Step & Owner & Minimum & Average & Maximum \\
\hline $\mathrm{P}_{1}$ & Production selection/quote & Sales team & 5 & 7 & 9 \\
\hline $\mathrm{P}_{2}$ & Order confirmation between customer \& company & Sales team & 2 & 4 & 7 \\
\hline $\mathrm{P}_{3}$ & Placing order for production & Procurement & 21 & 30 & 45 \\
\hline $\mathrm{P}_{4}$ & Containers ready for shipping & Procurement & 7 & 14 & 21 \\
\hline $\mathrm{P}_{5}$ & Forwarder collects goods from the port & Procurement & 7 & 10 & 15 \\
\hline $\mathrm{P}_{6}$ & Goods available in company warehouse & Procurement & 1 & 7 & 21 \\
\hline $\mathrm{P}_{7}$ & Delivery & Project coordinator & 2 & 4 & 14 \\
\hline $\mathrm{P}_{8}$ & Installation & Project coordinator & 7 & 9 & 20 \\
\hline $\mathrm{P}_{9}$ & Inventory + photographs & Project coordinator & 2 & 5 & 10 \\
\hline \multicolumn{3}{|c|}{ Total } & 53 & 90 & 162 \\
\hline
\end{tabular}

$$
* f_{X(i, j)} \sum_{j=1}^{J} \sum_{i=1}^{I} \sigma_{X(i, j)}
$$

subject to: $\operatorname{IMSR}_{i, j}\left(x_{s}\right) \geq \operatorname{IMSR}^{T}, \quad i=1,2, \ldots, I$

$$
\begin{aligned}
& x_{s}^{L} \leq x_{s} \leq x_{s}^{U}, \quad j=1,2, \ldots, J \\
& x_{s} \geq 0, \quad s=1,2, \ldots, S,
\end{aligned}
$$

where $\operatorname{IMSR}\left(x_{s}\right)$ is the reliability and the reliability target is $\operatorname{IMSR}^{T}\left(x_{s}\right) . C_{X(i, j)}$ is the cost function of node type $X$, number $i$, in level $j . \sigma_{X(i, j)}$ represents the standard deviation (delay due to uncertainty) of the inventory cycle time function of node type $X$, with the indices mentioned earlier. $\mu_{X(i, j)}$ represents the mean of the inventory cycle time function of node type $X . \mathbf{W}$ is the weight attached based on decision maker preference. $x_{s}^{L}$ and $x_{s}^{U}$ are the lower and upper limits of the design variable, respectively.

2.3. RBRDO of Inventory Management System Summaries. The procedure for RBRDO of an Inventory Management System can be summarized as follows.

Step 1. Collect data.

Step 2. (a) Generate more data points via MCS; (b) generate an initial set of sample points.

Step 3. Perform reliability analysis at the current design $\mathbf{x}$.

Step 4. Execute the developed RBRDO model.

Step 5. (a) Check the convergence criteria. (b) If they converged, the optimum design has been obtained. (c) If they did not converge, repeat Step 2(b) through Step 5.

\section{Results and Discussion}

3.1. Case Study. The developed method was applied to the inventory management system of a furniture company in Jeddah, Saudi Arabia. This company provides a wide range of furniture from North America, Europe, and the Far East to match client designs within budgets. The inventory management system consists of 9 stages, each aimed at different types of operations. Table 1 shows primary data collected from the company and describes the average, minimum, and maximum number of days that each entity (department) requires for each step in the process.

3.2. Data Collection. This study used primary data collected in coordination with the furniture company to verify and validate the model. Primary data was used via several techniques such as surveys, direct observations, and interviews. This data was collected directly via first-hand experience. Moreover, it included quantitative and qualitative attributes of variables obtained by the sales department.

One of the main obstacles faced during this research was the limited supply of data points. Monte Carlo simulations (MCSs) were used to overcome this problem. The Monte Carlo simulation is a mathematical technique that allows generation of data from limited data resources. The main aim of this technique is to help in decision-making via the range and possible outcomes generated. This method helps to obtain numerical solutions to problems that are too complex to solve analytically. It offers several advantages, including ease of use and the flexibility to use the probabilities generated from the model. In addition, the mathematics required are quite basic. MCSs were used to generate more than 50,000 extra numerical data points, which helped in developing the RBRDO model. The cost function was presented as an exponential distribution. Thus, nonlinear programming was used to solve the model. The exponential distribution $e^{-\lambda}$ is a probability distribution that describes the relationship between cost and time. Figure 4 shows that shipping and processing costs decrease when process durations increase (late due dates).

3.3. Case Study Results. The first step was to model the inventory system using MATLAB R2014a. Then the current performance of the inventory management system was evaluated using (2). The collected data and MCS indicate that the current total cycle time of an order is approximately 107 days, and the IMSR is $88.28 \%$, as shown in Table 2 . Thus, if a customer places an order it takes 107 days to complete, and the probability of completing the order on time is $88.28 \%$. Thus, 
TABLE 2: Initial design variables.

\begin{tabular}{ccccccccccc}
\hline $\mathrm{P}_{1}$ & $\mathrm{P}_{2}$ & $\mathrm{P}_{3}$ & $\mathrm{P}_{4}$ & $\mathrm{P}_{5}$ & $\mathrm{P}_{6}$ & $\mathrm{P}_{7}$ & $\mathrm{P}_{8}$ & $\mathrm{P}_{9}$ & Total cycle time (TCT) & Initial reliability \\
\hline 7.1 & 4.5 & 33 & 14 & 11 & 11 & 7.6 & 13.4 & 6 & 107.52 & $88.2 \%$ \\
\hline
\end{tabular}

TABLE 3: Optimized points required to reach the delivery target.

\begin{tabular}{llllccccccc}
\hline $\mathrm{P}_{1}$ & $\mathrm{P}_{2}$ & $\mathrm{P}_{3}$ & $\mathrm{P}_{4}$ & $\mathrm{P}_{5}$ & $\mathrm{P}_{6}$ & $\mathrm{P}_{7}$ & $\mathrm{P}_{8}$ & $\mathrm{P}_{9}$ & Design Max TCT & Design IMSR \\
\hline 5 & 6.6 & 21 & 7.3 & 7 & 5.9 & 8 & 7 & 5.8 & 73.5 \\
\hline
\end{tabular}

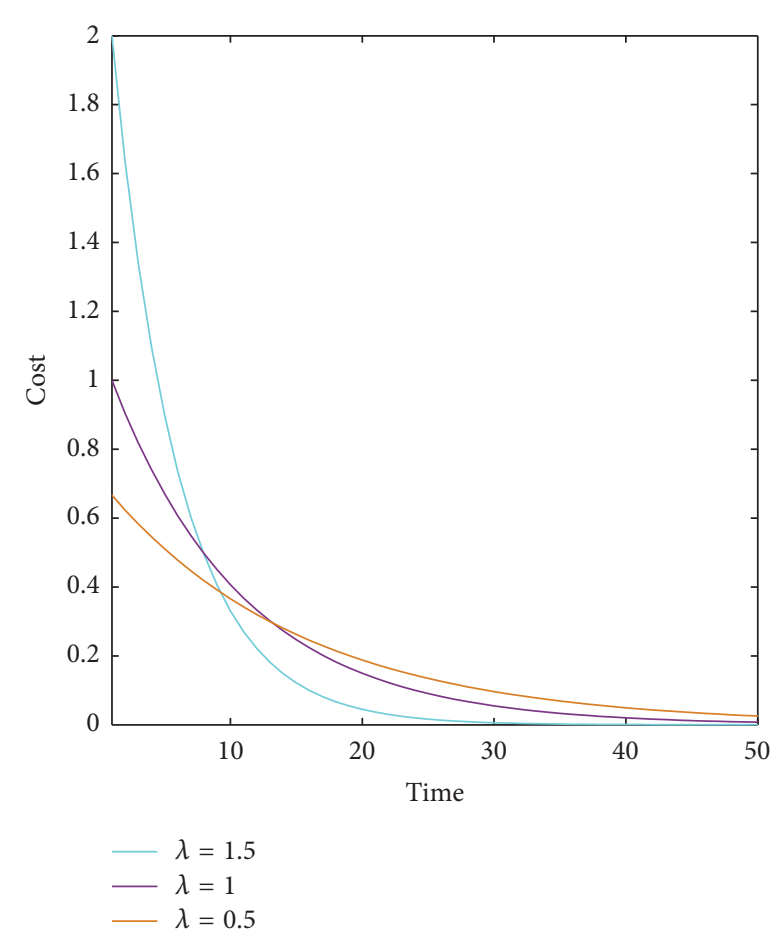

Figure 4: Relationship between cost and due dates.

the company should tell their customers that the order will require approximately 107 days. After this initial reliability evaluation, the design optimization model was applied by using (3) to modify the design and find the optimum total cycle time and/or satisfy reliability requirements.

To improve the initial reliability, the company could reduce the cycle time or adjust the schedule or both. For the former, the company could expedite one of the processes by adding more workers to the installation phase $\left(\mathrm{P}_{8}\right)$. It could also change delivery methods to reduce $\mathrm{P}_{7}$. Multiple scenarios have been implemented using MATLAB R2014a and (1)-(3). One such scenario improves the IMSR from $88.2 \%$ to $90.16 \%$ by adjusting the schedule without changing the actual cycle time. To achieve this, the company should tell the customer their order will require approximately 110 days instead of 107 days. Thus, the model is able to help with project scheduling in order to satisfy reliability requirements.

In another scenario, the company requests a design that can complete all processes in 70 days, with $95 \%$ of IMSR. Here, the model helps by assigning durations to each activity in order to satisfy due date and IMSR requirements. RBRDO

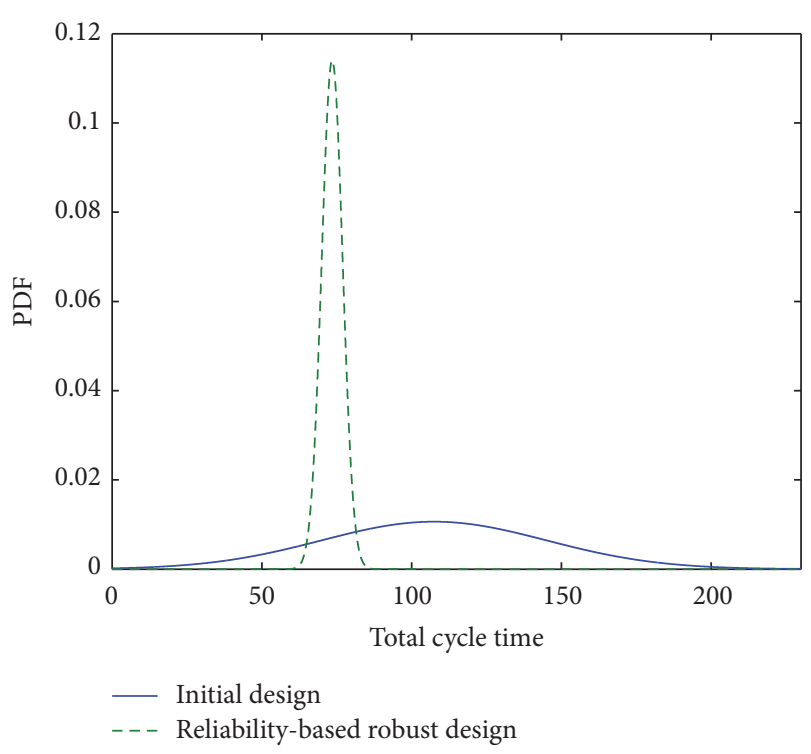

FIGURE 5: Results from the RBRDO model.

was applied to this problem, and the results are shown in Table 3.

Table 3 shows the decision variable of each task (time needed to accomplish each task) required to complete the order on time with $95 \%$ reliability. For example, delivery $\left(\mathrm{P}_{7}\right)$ should not take more than 8 days and installation $\left(\mathrm{P}_{8}\right)$ should not take more than 7 days if a 95\% IMSR is to be maintained. To determine the best result, model execution (optimization) was repeated several times to produce the optimized points shown in Table 3 . The new design satisfies the reliability requirement. Also, the company is $95 \%$ sure that the order will be delivered on time. Table 4 shows the cost functions determined using MATLAB.

Table 4 shows the cost of completing the project while satisfying reliability requirements at every iteration during RBRDO. It also shows that the cost of maintaining 95\% reliability decreases from $6.092591 e^{+06}$ to 173393.6728 . Figure 5 compares the PDFs of the initial design and the RBRD. The RBRD has less delay (variation) and a faster cycle time. Also, when comparing initial design and RBRD it is clear that the RBRD has the lowest cycle time while meeting reliability requirements. This optimization model determines the optimal IMSR value required for each stage of the IMS. Thus, we can conclude that developed RBRDO model can minimize costs while satisfying the reliability requirements. 
TABLE 4: Cost functions obtained after each iteration.

\begin{tabular}{|c|c|}
\hline Iteration & Cost $(\$)$ \\
\hline 0 & $6.092591 e+06$ \\
\hline 1 & $3.407595 e+06$ \\
\hline 2 & $2.819751 e+06$ \\
\hline 3 & $2.670462 e+06$ \\
\hline 4 & $2.603249 e+06$ \\
\hline 5 & $2.132391 e+06$ \\
\hline 6 & $1.343782 e+06$ \\
\hline 7 & $6.404783 e+05$ \\
\hline 8 & $5.742168 e+05$ \\
\hline 9 & $5.739864 e+05$ \\
\hline 10 & $5.405386 e+05$ \\
\hline 11 & $5.083312 e+05$ \\
\hline 12 & $4.506476 e+05$ \\
\hline 13 & $3.197391 e+05$ \\
\hline 14 & $2.860919 e+05$ \\
\hline 15 & $2.856679 e+05$ \\
\hline 16 & $2.850551 e+05$ \\
\hline 17 & $2.850489 e+05$ \\
\hline 18 & $2.850320 e+05$ \\
\hline 19 & $2.160011 e+05$ \\
\hline 20 & $2.159386 e+05$ \\
\hline 21 & $1.890276 e+05$ \\
\hline 22 & $1.806205 e+05$ \\
\hline 23 & $1.776129 e+05$ \\
\hline 24 & $1.767619 e+05$ \\
\hline 25 & $1.763392 e+05$ \\
\hline 26 & $1.748977 e+05$ \\
\hline 27 & $1.738370 e+05$ \\
\hline 28 & $1.734791 e+05$ \\
\hline 29 & $1.733999 e+05$ \\
\hline 30 & $1.733938 e+05$ \\
\hline 31 & $1.733937 e+05$ \\
\hline 32 & $1.733937 e+05$ \\
\hline 33 & $1.733937 e+05$ \\
\hline 34 & 173393.6728 \\
\hline
\end{tabular}

By applying the developed RBRDO model, the required reliability is achieved, all constraints are satisfied, and the impact of uncertainty is minimized as shown in Figure 5.

To investigate how reliability influences the total cost, different scenarios with various reliability rates were simulated. This investigation is summarized in Figures 6 and 7.

Figure 6 shows that the cost increases nonlinearly with the reliability requirements. For example, if the required IMSR is $70 \%$ the cost is $\$ 27,500$, and this cost increases to $\$ 100,000$ if the reliability requirement increases to $90 \%$. Figure 7 shows that applying the RBRDO achieves the reliability target and reduces variation. Moreover, the RBRDO can shift and adjust the total project cycle time based on the due date and reliability requirements. Figure 7 shows that the variation and cycle time decrease when reliability increases.

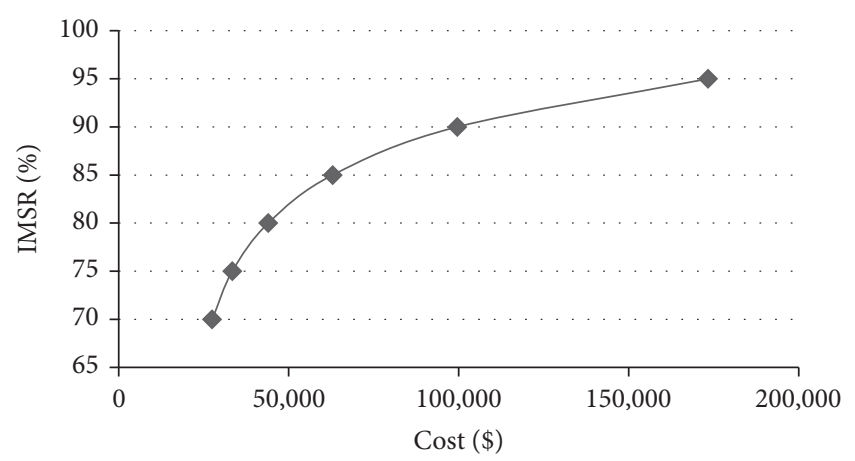

FIgURE 6: Cost of increasing the IMSR.

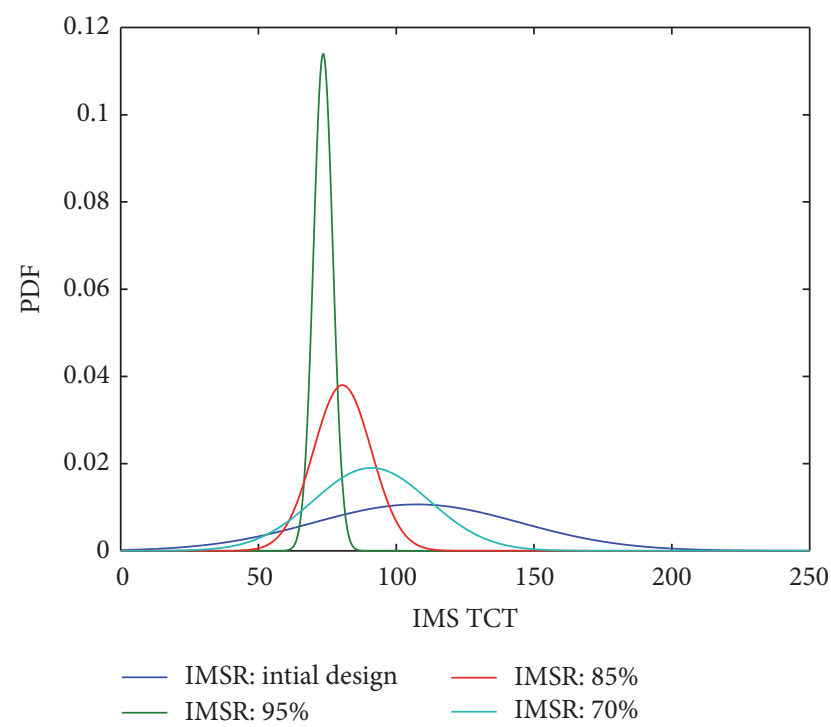

FIGURE 7: Distributions of the mean TCT at different IMSRs.

For example, a process with $95 \%$ reliability has lower cycle time and variation than one with $85 \%$ reliability.

Applying the RBRDO allows businesses to control reliability requirements while minimizing variation (impacts of uncertainty), while minimizing total cycle time and cost. This allows identification of activities that should be improved and the level of improvement required to achieve reliability targets. In addition, the proposed model helps to balance cost and reliability requirements, while also minimizing the impacts of product movement uncertainty.

\section{Conclusion}

IMSs are critical to many businesses. The primary objective of inventory management is to determine and control stock levels to minimize cost and achieve customer satisfaction. To achieve this, multiple design tools were applied to RBRDO development in order to help design a reliable IMS. These techniques include Monte Carlo simulation, deterministic nonlinear programing, and stochastic nonlinear programing. In addition, Microsoft Excel solver and MATLAB were used for modeling and mathematical simulation. 
This research contributed primarily to IMS evaluation and design optimization. Equations (1) and (2) can be used to evaluate the reliability of each task in an inventory system, as well as overall IMS reliability. Equation (3) helps to design a cost-efficient, reliable, and robust system while coping with uncertainty. In other words, the RBRDO model can help with task scheduling to satisfy reliability requirements, as well as with determining time limits for each activity to satisfy due date and reliability requirements. The furniture company case study verified and validated the models. The case study showed that RBRDO can be used to design a reliable and robust IMS, while minimizing the impact of uncertainty. This positively impacts customer satisfaction. The model helps to determine the optimal time for each task, reducing delays and increasing the level of client trust and satisfaction.

\section{Conflicts of Interest}

The author declares that there are no conflicts of interest regarding the publication of this article.

\section{Acknowledgments}

The author would like to acknowledge Deanship of Graduate Studies and Scientific Research at Effat University for their efforts and support. The author also acknowledges Ms. Waffaa Alireza for her data collection efforts and support.

\section{References}

[1] M. Sani, "Applicable Inventory Control Models for Agricultural Business Managers: Issues and Concerns," Trends in Agricultural Economics, vol. 7, no. 1, pp. 11-25, 2014.

[2] R. Ernst, J. Guerrero, and A. Roshwalb, "A quality control approach for monitoring inventory stock levels," Journal of the Operational Research Society, vol. 44, no. 11, pp. 1115-1127, 1993.

[3] L. M. Ellram and M. C. Cooper, "Supply chain management: It's all about the journey, not the destination," Journal of Supply Chain Management, vol. 50, no. 1, pp. 8-20, 2014.

[4] K. K. Krishnan, A. T. Almaktoom, and P. Udayakumar, "Optimisation of stochastic assembly line for balancing under high variability," International Journal of Industrial and Systems Engineering, vol. 22, no. 4, pp. 440-465, 2016.

[5] S. A. H. Zaidi, S. A. Khan, and F. Dweiri, "Implementation of Inventory Management System in a furniture company," International Journal of Engineering and Technology, vol. 2, no. 8, pp. 5-6, 2012.

[6] V. Dubourg, B. Sudret, and J.-M. Bourinet, "Reliability-based design optimization using kriging surrogates and subset simulation," Structural and Multidisciplinary Optimization, vol. 44, no. 5, pp. 673-690, 2011.

[7] R. Widarsyah, The Impact of Airport Service Quality Dimension on Overall Airport Experience and Impression, Digital Scholarship@UNLV, 2013.

[8] M. Cosmas and G. R. Chingarande, "An evaluation of passenger satisfaction on service quality delivered at an airport in Namibia: A quality perspective approach," International Journal of Management, IT and Engineering, vol. 3, no. 1, pp. 292-304, 2013.
[9] A. T. Almaktoom and K. K. Krishnan, "Reliability-based Robust Design Optimization of Dynamic Supply Chain Network," in Proceedings of the International Conference on Industrial Engineering and Operations Management, pp. 2510-2519, 2016.

[10] B. D. Youn and K. K. Choi, "Selecting probabilistic approaches for realiability-based design optimization," AIAA Journal, vol. 42, no. 1, pp. 124-131, 2004.

[11] M. Cid Montoya, M. Costas, J. Díaz, L. E. Romera, and S. Hernández, "A multi-objective reliability-based optimization of the crashworthiness of a metallic-GFRP impact absorber using hybrid approximations," Structural and Multidisciplinary Optimization, vol. 52, no. 4, pp. 827-843, 2015.

[12] I. Arsenyev, F. Duddeck, and A. Fischersworring-Bunk, "Efficient surrogate-based robust shape optimization for vane clusters," in Proceedings of the 16th AIAA/ISSMO Multidisciplinary Analysis and Optimization Conference, 2015, p. 3361, USA, June 2015.

[13] A. Chaudhuri, G. Waycaster, N. Price, T. Matsumura, and R. T. Haftka, "NASA uncertainty quantification challenge: An optimization-based methodology and validation," Journal of Aerospace Information Systems, vol. 12, no. 1, pp. 10-34, 2015.

[14] P. Kanakasabai, Approaches for Reliability Based Design Optimization, The University of Wisconsin-Milwaukee, 2011.

[15] M. Mohammad, M. P. Kaminskiy, and V. Krivtsov, Reliability Engineering and Risk Analysis: A Practical Guide, CRC Press, 2009.

[16] D. M. Byrne and S. Taguchi, "Taguchi approach to parameter design,” Quality Progress, vol. 20, no. 12, pp. 19-26, 1987.

[17] D. Roos, U. Adam, and C. Bucher, "Robust design optimization," in Proceedings of the 3rd Weimarer Optimierung-und Stochastiktage, 2006.

[18] P. Wang, C. Hu, and B. D. Youn, "A generalized complementary intersection method (GCIM) for system reliability analysis," Journal of Mechanical Design, Transactions of the ASME, vol.133, no. 7, Article ID 071003, 2011.

[19] P. Wang, Z. Wang, and A. T. Almaktoom, "Dynamic reliabilitybased robust design optimization with time-variant probabilistic constraints," Engineering Optimization, vol. 46, no. 6, pp. 784-809, 2014.

[20] B. D. Youn, K. K. Choi, and L. Du, "Enriched performance measure approach for reliability-based design optimization," AIAA Journal, vol. 43, no. 4, pp. 874-884, 2005.

[21] X. Du and W. Chen, "Sequential optimization and reliability assessment method for efficient probabilistic design," Journal of Mechanical Design, vol. 126, no. 2, pp. 225-233, 2004.

[22] A. T. Almaktoom, K. K. Krishnan, P. Wang, and S. Alsobhi, "Assurance of system service level robustness in complex supply chain networks," International Journal of Advanced Manufacturing Technology, vol. 74, no. 1-4, pp. 445-460, 2014.

[23] S. Axsäter, "Chapter 4 Continuous review policies for multilevel inventory systems with stochastic demand," Handbooks in Operations Research and Management Science, vol. 4, no. C, pp. 175-197, 1993.

[24] S. Suh, M. Lenzen, G. J. Treloar et al., "System boundary selection in life-cycle inventories using hybrid approaches," Environmental Science and Technology, vol. 38, no. 3, pp. 657-664, 2004.

[25] J. Resurreccion and J. R. Santos, "Multiobjective Prioritization Methodology and Decision Support System for Evaluating Inventory Enhancement Strategies for Disrupted Interdependent Sectors," Risk Analysis, vol. 32, no. 10, pp. 1673-1692, 2012. 
[26] E. Arıkan, J. Fichtinger, and J. M. Ries, "Impact of transportation lead-time variability on the economic and environmental performance of inventory systems," International Journal of Production Economics, vol. 157, no. 1, pp. 279-288, 2014.

[27] S. Birim and C. Sofyalioglu, "Evaluating vendor managed inventory systems: how incentives can benefit supply chain partners," Journal of Business Economics and Management, vol. 18, no. 1, pp. 163-179, 2017.

[28] S. M. Mousavi, A. Bahreininejad, S. N. Musa, and F. Yusof, "A modified particle swarm optimization for solving the integrated location and inventory control problems in a two-echelon supply chain network," Journal of Intelligent Manufacturing, vol. 28, no. 1, pp. 191-206, 2017.

[29] H. Juan, W. Jian, J. Xianglin, X. Chen, and L. Chen, “The longterm extreme price risk measure of portfolio in inventory financing: an application to dynamic impawn rate interval," Complexity, vol. 20, no. 5, pp. 17-34, 2015.

[30] A. T. Almaktoom, K. K. Krishnan, P. Wang, and S. Alsobhi, "Cost efficient robust global supply chain system design under uncertainty," International Journal of Advanced Manufacturing Technology, vol. 85, no. 1-4, pp. 853-868, 2016.

[31] A. K. Alsaadi, A. T. Almaktoom, and K. K. Krishnan, "Reliability evaluation and design optimization of inventory management system," in Proceedings of the International Conference on Industrial Engineering and Operations Management, pp. 922-927, 2016. 


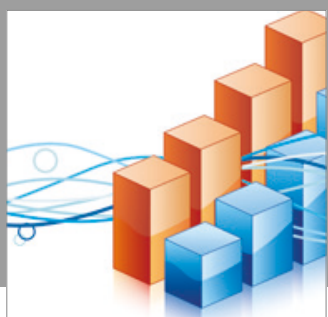

Advances in

Operations Research

vatersals

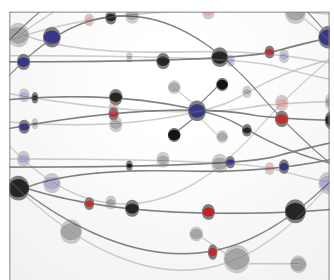

\section{The Scientific} World Journal
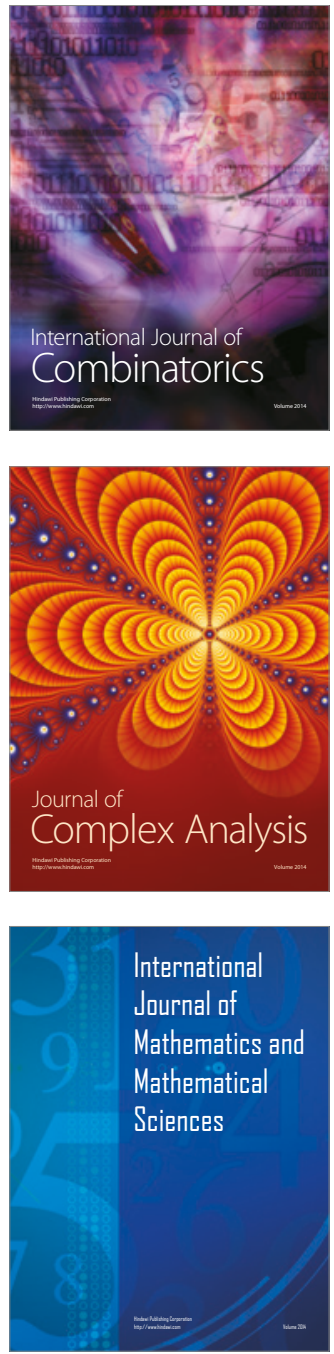
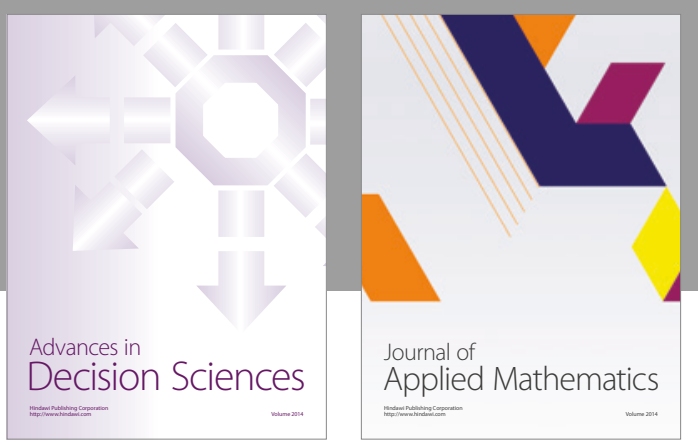

Algebra

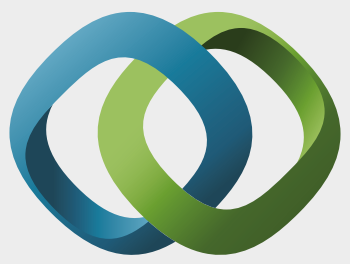

\section{Hindawi}

Submit your manuscripts at

https://www.hindawi.com
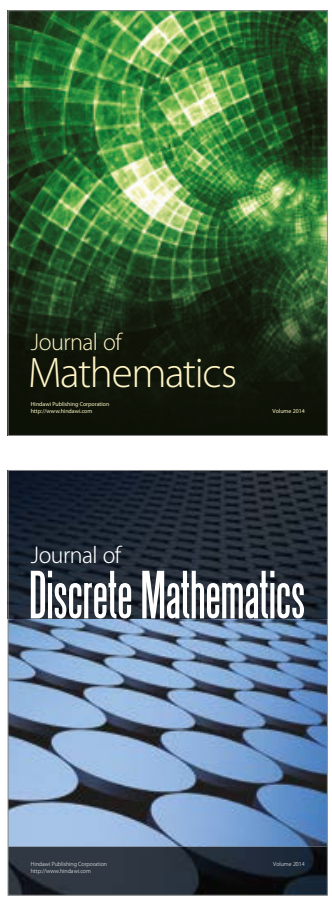

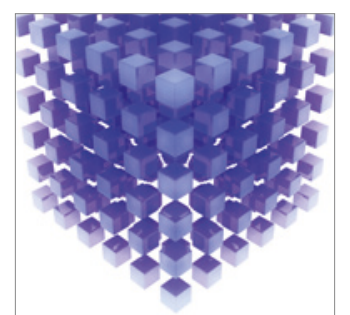

Mathematical Problems in Engineering
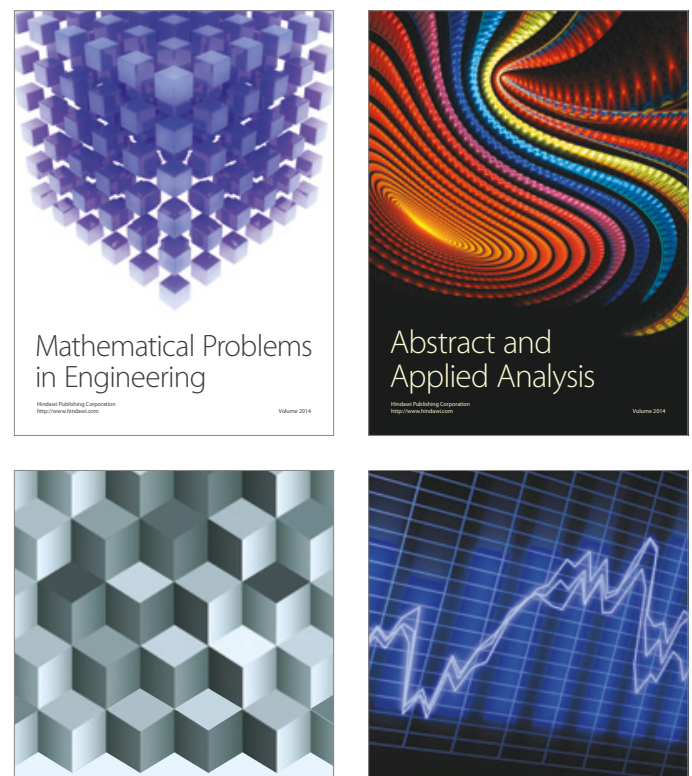

Journal of

Function Spaces

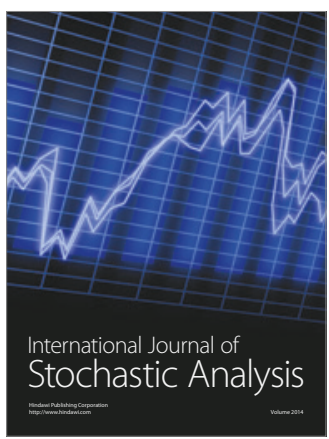

Probability and Statistics
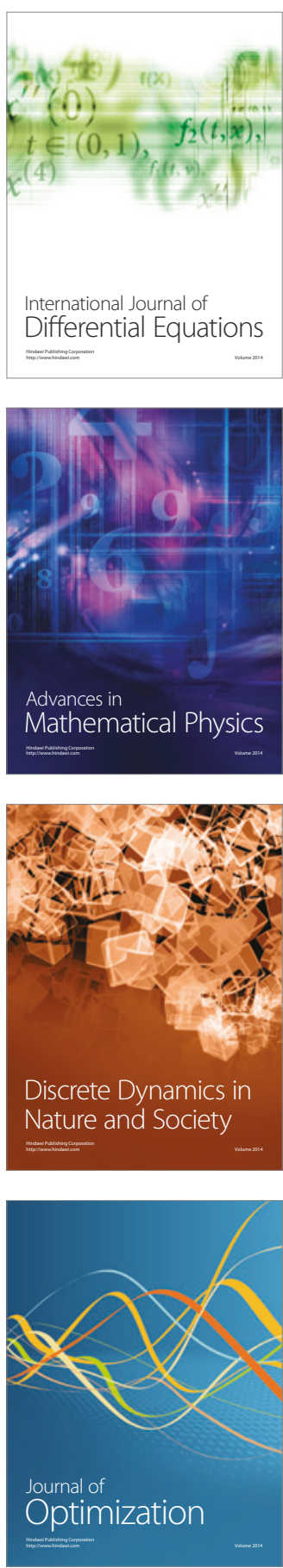